\title{
Role of imaging (MDCT) in ocular and orbital lesions
}

\author{
PK Shah ${ }^{1}$, RK Rauniyar ${ }^{1}$, MK Gupta ${ }^{1}$, BP Badhu ${ }^{2}$ \\ Department of Radio-diagnosis and Medical Imaging ${ }^{1}$, Department of Ophthalmology ${ }^{2}$ \\ B.P. Koirala Institute of Health Sciences, Dharan, Nepal
}

\begin{abstract}
Background: Radiological imaging is still important to diagnose ocular and orbital abnormalities. Computed tomography is the first-line imaging modality for orbital imaging in the acute setting with magnetic resonance imaging playing an important secondary role. Objective: To assess the role of multidectector computed tomography (MDCT) in diagnosis of ocular and orbital lesions. To describe the imaging features of various orbital and ocular lesions on MDCT. Methods: A prospective cross-sectional study was conducted on 50 patients in B.P. Koirala Institute of Health Sciences, over the period of one year (from July 2013 to June 2014). All the patients with clinical suspicion of ocular and orbital lesions, referred from the ophthalmology department for CT scan were included in this study. Results: Out of 50 cases 4 were traumatic and 46 were non traumatic cases. Retinoblastoma was most common non traumatic lesion in our study. We compared MDCT diagnosis and final diagnosis which was based on histopathology/ per operative finding, FNAC, clinical response to treatment, supportive laboratory (biochemical/ microbiological) findings and supportive findings on other radiological investigations (USG and MRI). The sensitivity of MDCT in diagnosing ocular and orbit lesions was $95.65 \%$. Conclusion: MDCT has important role in characterization and diagnosis of the lesions, surgical planning and follow up of patient with various ocular and orbital pathologies. MDCT is better for evaluation of bones and detection of calcifications and to discern the location, extent and configuration of the lesions. Therefore MDCT is an ideal radiological method for evaluation of various ocular and orbital lesions.
\end{abstract}

Key words: MDCT, USG, MRI.

\footnotetext{
Address for correspondence

Pratima Kumari Shah

Department of Radio-diagnosis and Medical Imaging

B.P. Koirala Institute of Health Sciences, Dharan
} 


\section{Introduction}

Radiological imaging provides crucial information regarding ocular and orbital abnormalities. The various imaging modalities used for the evaluation of orbit are plain film radiography, ultrasonography, computed tomography (CT) scan and magnetic resonance imaging (MRI).

With advent of cross-sectional imaging plain radiograph has minimal role, except to rule out foreign body before doing MRI.

Ultrasonography is widely available, non-invasive, diagnostic modality particularly useful in evaluation of intraocular lesions $1 /$ pathology in posterior segment of the eye.

Computed tomography is the first-line imaging modality for orbital imaging in the acute setting with magnetic resonance imaging playing an important secondary role ${ }^{2}$. CT is generally more widely available and cheaper and superior to MRI for delineation of osseous structures and calcification. CT and MRI often provide complementary roles in orbital imaging. MRI has advantages over CT in its superior soft tissue contrast, its ability to image the orbit and intracranial structures.

Orbital imaging play an important role in diagnosis, narrowing the differential diagnosis, guiding for further work up, various guided interventional procedures and also provide a road map to the surgeon.
Since ocular and orbital lesions being a common problem in this part of Nepal and no study is available to deal the magnitude of the problem. Hence, this study was planned to assess the role of MDCT in ocular and orbital lesions in eastern Nepal.

\section{Methods}

The study was carried out on prospective cross-sectional basis over a period of one year (July 2013 to June 2014) and the study was reviewed and approved by the institutional ethical review board.

Taking into account the number of patients referred for CT scan of orbit for the evaluation of suspected ocular and orbital lesions per year in the past in our institution, we had decided to include at least 40 cases. All the patients with clinical suspicion of ocular and orbital lesions, referred from the ophthalmology department for CT scan, irrespective of age and gender were included in this study and the patients with post operative history and with history of chemo/radiotherapy were excluded from the study.

CT scans was performed with standard protocol on Hitachi Eclos 16 slice multidetector CT. Axial images of the orbit was obtained in supine position starting from infra-orbital margin to supra-orbital margin. The plane of the axial orbital imaging was parallel to the infra-orbitomeatal line. Further 
scanning was extended depending upon pathology. The volumetric sectional images were acquired with tube current 150-175 mA and tube voltage120-140 kVp. The matrix size was $512 \times 512$ and slice thickness was $2.5 \mathrm{~mm}$ with no interslice gaping and the raw datas were processed and multiplanar (MPR) and three dimensional (3-D) reconstructions. Non ionic intravenous contrast agent was used wherever necessary.

The final diagnosis was made on the basis of histopathological examination of operative specimen/ per operative finding, FNAC, clinical response to treatment (on follow up), supportive biochemical/ microbiological findings and supporting finding on other radiological investigations (USG and MRI) depending on the nature of the pathologies.

The collected data5 were entered in computer through Microsoft Excel programme 2007 and converted into SPSS 11.5 version for statistical analysis. For inferential statistics, sensitivity and specificity were calculated to find out the relationship with gold standard test \& other related test. ' $P$ ' value was calculated using chi-square test and value of $<0.05$ was considered statistically significant.

\section{Results}

50 (100 eyes) patients with clinical suspicion of ocular and orbital lesions underwent CT scan, out of which 59 eyes were affected eyes (in 9 patients the lesions were bilateral). Out of total 59, 55 eyes had non-traumatic and 4 eyes had traumatic lesions. Age of patients in our study ranged from 1 to 65 years and male to female ratio of 1.2:1.

Broad categories of the non-traumatic lesions in total 55 diseased are shown in table 1

\section{Table 1: Broad category of non-traumatic ocular and orbital lesions on MDCT}

\begin{tabular}{|l|l|l|}
\hline \multicolumn{1}{|c|}{ Category } & Frequency $(\mathrm{n}=55)$ & Percentage (\%) \\
\hline $\begin{array}{l}\text { Neoplasm } \\
\text { Malignant } \\
\text { Benign }\end{array}$ & $\begin{array}{l}26 \\
20 \\
6\end{array}$ & 47.27 \\
\hline Infective and inflammatory lesion & 20 & 36.66 \\
\hline Congenital and developmental lesions & 3 & 5.45 \\
\hline Parasitic & 2 & 3.63 \\
\hline
\end{tabular}




\begin{tabular}{|l|l|l|}
\hline Vascular lesions & 1 & 1.81 \\
\hline Miscellaneous (bone and PNS lesions & 3 & 5.45 \\
\hline
\end{tabular}

In 55 non-traumatic eyes only 46 diseased Retinoblastoma was the commonest non eyes were available for final diagnosis in our traumatic lesion (Table 2). study.

Table 2: Final diagnosis of ocular and orbital lesions based on histopathology/ per operative finding, FNAC, clinical response to treatment, supportive laboratory (biochemical/ microbiological) findings and supportive findings on other radiological investigations (USG and MRI).

\begin{tabular}{|c|c|c|c|c|c|c|c|c|c|}
\hline Disease & $\begin{array}{c}\text { Dis- } \\
\text { eased } \\
\text { eyes on } \\
\text { MDCT } \\
(n=55)\end{array}$ & $\begin{array}{l}\text { Eyes } \\
\text { availa- } \\
\text { ble for } \\
\text { final } \\
\text { diag- } \\
\text { nosis }\end{array}$ & $\begin{array}{c}\text { Per- } \\
\text { operative } \\
\text { finding/ } \\
\text { Histopa- } \\
\text { thology }\end{array}$ & FNAC & $\begin{array}{l}\text { Biochem- } \\
\text { ical/ } \\
\text { microbio- } \\
\text { logical } \\
\text { support- } \\
\text { ing find- } \\
\text { ings. }\end{array}$ & $\begin{array}{c}\text { Re- } \\
\text { sponse } \\
\text { to treat- } \\
\text { ment }\end{array}$ & $\begin{array}{l}\text { USG/ } \\
\text { doppler } \\
\text { support- } \\
\text { ing find- } \\
\text { ing }\end{array}$ & $\begin{array}{l}\text { MRI } \\
\text { sup- } \\
\text { port- } \\
\text { ing } \\
\text { find- } \\
\text { ing }\end{array}$ & $\begin{array}{l}\text { Total } \\
\text { final } \\
\text { diagno- } \\
\text { sis }\end{array}$ \\
\hline $\begin{array}{l}\text { Retinoblas- } \\
\text { toma }\end{array}$ & 15 & 12 & 5 & 3 & - & - & - & 3 & 11 \\
\hline $\begin{array}{l}\text { Orbital cel- } \\
\text { lulitis }\end{array}$ & 5 & 5 & - & - & - & 5 & - & - & 5 \\
\hline $\begin{array}{l}\text { Preseptal } \\
\text { cellulitis }\end{array}$ & 3 & 3 & - & & 1 & 3 & - & - & 3 \\
\hline $\begin{array}{l}\text { Endocrine } \\
\text { Orbitopathy }\end{array}$ & 6 & 6 & - & - & 6 & 6 & - & - & 6 \\
\hline $\begin{array}{l}\text { Isolated } \\
\text { Dermoid } \\
\text { cyst }\end{array}$ & 5 & 3 & 3 & - & - & - & - & - & 3 \\
\hline
\end{tabular}




\begin{tabular}{|c|c|c|c|c|c|c|c|c|c|}
\hline $\begin{array}{l}\text { Orbital } \\
\text { pseudotu- } \\
\text { mor }\end{array}$ & 4 & 4 & - & - & - & 3 & - & - & 3 \\
\hline $\begin{array}{l}\text { Myocysti- } \\
\text { cercosis }\end{array}$ & 2 & 2 & - & - & - & 2 & 2 & - & 2 \\
\hline $\begin{array}{l}\text { Optic nerve } \\
\text { glioma }\end{array}$ & 2 & 1 & - & - & - & - & - & 1 & 1 \\
\hline $\begin{array}{l}\text { Endoph- } \\
\text { thalmitis }\end{array}$ & 2 & 2 & 2 & - & - & - & - & - & 2 \\
\hline PHPV & 1 & 1 & - & - & - & - & - & 1 & 1 \\
\hline Staphyloma & 1 & 1 & - & - & - & - & - & 1 & 1 \\
\hline $\begin{array}{l}\text { Hemangi- } \\
\text { oma }\end{array}$ & 1 & 1 & - & - & - & - & - & 1 & 1 \\
\hline $\begin{array}{l}\text { Choroidal } \\
\text { melanoma }\end{array}$ & 1 & 1 & 1 & - & - & - & - & - & 1 \\
\hline $\begin{array}{l}\text { Orbital lym- } \\
\text { phoma }\end{array}$ & 1 & 0 & - & - & - & - & - & - & 0 \\
\hline $\begin{array}{l}\text { Fronto- } \\
\text { ethmoidal } \\
\text { mucocele }\end{array}$ & 1 & 1 & 1 & 1 & - & - & - & - & 1 \\
\hline CCF & 1 & 1 & - & & - & - & 1 & 1 & 1 \\
\hline $\begin{array}{l}\text { Frontal si- } \\
\text { nus carci- } \\
\text { noma }\end{array}$ & 1 & 0 & - & - & - & - & - & - & 0 \\
\hline $\begin{array}{l}\text { Buphthal- } \\
\text { mos }\end{array}$ & 1 & 1 & - & - & - & - & 1 & 1 & 1 \\
\hline $\begin{array}{l}\text { Dermoid } \\
\text { cyst with } \\
\text { coloboma }\end{array}$ & 1 & 0 & - & - & - & - & - & - & 0 \\
\hline
\end{tabular}




\begin{tabular}{|l|l|l|l|l|l|l|l|l|l|}
\hline $\begin{array}{l}\text { Frontal } \\
\text { bone fibr- } \\
\text { ous dyspla- } \\
\text { sia }\end{array}$ & 1 & 1 & 1 & - & & - & - & - & 1 \\
\hline $\begin{array}{l}\text { Pleomor- } \\
\text { phic ade- } \\
\text { noma of } \\
\text { lacrimal } \\
\text { gland }\end{array}$ & 0 & 0 & 0 & 1 & - & - & - & - & 1 \\
\hline $\begin{array}{l}\text { Coats dis- } \\
\text { ease }\end{array}$ & 0 & 0 & 1 & - & - & - & - & - & 1 \\
\hline Total & 55 & 46 & & & & & & & \\
\hline
\end{tabular}

12 eyes of retinoblastoma were available for final diagnosis. One out of 12 was diagnosed as coats' disease and another as endophthalmitis on histopathological examination. One case diagnosed of endophthalmitis turned out to be retinoblastoma on histopathological examination. Therefore there were 11 eyes of retinoblastoma on final diagnosis. Our study showed that MDCT had sensitivity of $90.90 \%$ and specificity of $94.28 \%$ in the diagnosis of retinoblastoma.

MDCT showed heterogeneous enhancing ocular mass in the posterior segment of the globe in all the cases, 6 had endophytic growth and 5 had exophytic growth of the tumor. Among 5 exophytic growth one had associated retinal detachment. There was infiltration of extraocular muscle, optic nerve and optic chiasma with contiguous supra-sellar mass in one of the cases of retinoblastoma. Out of 3 (6 eyes) bilateral cases, one had leptomeningeal metastasis and another one had associated pineaoblastoma (i.e trilateral retinoblastoma) with leptomeningeal metastasis and hydrocephalus. Calcification was seen in 10 out of 11 eyes of retinoblastoma. MRI done in few cases as supportive investigation showed characteristic signal intensity. The lesion appeared hyeprintense on T1W and hypointense on T2W with respect to vitreous along with enhancement on post contrast study. Pineal body tumor was seen in 1 case along with intra cranial extension involving optic tract and chiasma. Leptomeningeal metastasis was also seen in 2 cases. 
In diagnosis of dermoid our study showed MDCT had sensitivity of $100 \%$ and specificity of $100 \%$. MDCT showed well defined heterogeneous soft tissue density lesion with fat density within in 2(66.66\%) cases and fat fluid level in 1 case. In 1 case there was erosion and in 1 case there was scalloping of underlying bone. In 1 case the lesion compressed the lacrimal gland. Foci of calcification were seen in 2 .

MDCT had sensitivity of $100 \%$, specificity of $100 \%$ in the diagnosis of orbital and preseptal cellulitis. MDCT finding showed increased density and stranding of retrobulbar fat and preseptal soft tissue thickening in orbital cellulitis along with thickening of exraocular muscle. Out of 5 eyes of orbital cellulitis 2 eyes had associated inflammation of lacrimal gland. One eye with orbital cellulitis showed abscess. Associated paranasal sinusitis was seen in 2 eyes of orbital cellulitis. MDCT showed oedema and thickening of preseptal soft tissue in all 3 eyes of preseptal cellulitis.

One out of 4 cases of orbital pseudotumor did not respond to steroid therapy and on FNAC it turned out to be pleomorphic adenoma of lacrimal gland. Therfore MDCT had sensitivity of $100 \%$, specificity of $97.67 \%$. Thyroid orbitopathy had sensitivity of $100 \%$, specificity of $100 \%$. MDCT finding in pseudotumor showed enlargement of extra ocular muscle right up to its tendinous insertion. Most common muscle involved was inferior rectus followed by medial rectus. Retrobulbar fat stranding was seen in $3(100 \%)$ case and proptosis in $2(66.66 \%)$ cases. CT scan in thyroid orbitopathy showed fusiform enlarged belly of extra ocular muscles in all 3 with sparing of tendeneous insertion. Most common muscle involved was inferior rectus followed by medial rectus and SR/LPS complex. Increased volume of retrobulbar fat leading to proptosis was seen in all 6 eyes.

One out of 2 cases of endophthalmitis was diagnosed as retinoblastoma in MDCT and one eye diagnosed as retinoblastoma turned out to be as endophthalmitis on histopathological examination (i.e. false negative). Therefore our study showed MDCT had sensitivity of $50 \%$, specificity of $98.97 \%$.

In myocysticercosis final diagnosis was based on USG supporting findings and on response to treatment (on follow up). On comparison our study showed MDCT had sensitivity of $100 \%$, specificity of $100 \%$. There were many diseases which presented single in number in our study and were correctly diagnosed giving sensitivity of $100 \%$. However it may not account for correct sensitivity because of small sample size. The disease presenting single in number included PHPV, staphyloma, choroidal melanoma, optic nerve glioma, and fronto-ethmoidal mucocele with orbital extension, frontal bone fibrous dysplasia, CCF, buphthalmos and 
capillary hemangioma. Over all sensitivity of MDCT in non-traumatic ocular and orbital lesions was $95.65 \%$.

In Myocysticercosis MDCT in both cases showed thickening of extraocular muscle with peripherally enhancing cystic lesion with eccentric hyperdens focus (scolex). A single case of PHPV showed a triangular retrolental band of soft tissue extending from the posterior surface of lens to posterior pole of globe showing mild enhancement on past contrast study. There was no e/o calcification seen. Final diagnosis was made by supportive MRI findings which showed typical triangular, retrolental vascular soft tissue mass with a central tissue stalk of hyaloid remnant connected to the optic disc. Vitreous was abnormally hyperintense on both $\mathrm{T} 1$ and T2-weighted sequences. Endophthalmitis showed preseptal soft tissue thickening along with heterogeneously enhancing soft tissue density lesion in intraviterous compartment. Staphyloma on MDCT showed focal bulge in limbal region. On MRI focal bulge with protrusion of the uveal tissue was seen. Hemangioma on MDCT showed ill defined enhancing mass lesion in supero-medial aspect of the orbit in extraconal space displacing eye ball laterally and slightly anteriorly causing proptosis and MRI showed ill defined, markedly enhancing mass lesion in superomedial aspect of the orbit in extraconal space with flow void on T2W image.
Choroidal melanoma on MDCT appeared as hyperdense, dome shaped intraocular soft tissue mass in the medial part of the globe with broad base towards coats of the eyeball projecting into vitreous cavity. Lesion showed strong enhancement on past contrast study along with mild associated retinal detachment and thickening of coat of eyeball involving optic nerve head region. USG and MRI were supporting our CT diagnosis. Color Doppler demonstrated flow within the lesion. Optic nerve glioma showed fusiform enlargement of optic nerve almost filling the intraconal space and causing widening of bony orbit and optic foramen and canal. The mass infiltrated the posterior globe and extraocular muscles were compressed by the mass and the lesion showed mild enhancement on post contrast study. Final diagnosis in this case was made based on supportive MRI findings which showed is to hypointense lesion on T1W and hyperintense on T2W images involving optic nerve. Frontal bone fibrous dysplasia on MDCT showed expansile mixed density (Osseous, lytic \& ground glass) lesion in frontal bone. CCF on MDCT showed enlarged and tortuous superior ophthalmic vein, enlarged extra-ocular muscle and engorgement of ipsilateral cavernous sinus. Filling of superior ophthalmic vein in arterial phase was seen in post contrast study. On USG there was dilated and tortuous superior ophthalmic vein on color Doppler showing arterialized flow on 
spectral analysis. For supporting our diagnosis MRI was done which showed flow void due to abnormal high flow in superior ophthalmic vein. Fronto-ethmoidal mucocele on MDCT showed mucoid soft tissue density lesion in ethmoidal sinus causing thinning and resorption of ethmoidal septa and destruction of floor of frontal sinus and medial wall of orbit along with extension into frontal sinus and bulging into orbit. Buphthalmos on MDCT appeared as enlarged globe (axial length $\sim 26 \mathrm{~mm}$ ) with atrophy of optic nerve. Among total 4 traumatic cases (4 affected eyes); orbital fracture was the most common finding, shown in table 3

Table 3: Spectrum of traumatic ocular and orbital lesions

\begin{tabular}{|l|l|l|}
\hline \multicolumn{1}{|c|}{ Disease } & Frequency $(\mathrm{n}=4)$ & Percentage (\%) \\
\hline Fracture & 3 & 75 \\
\hline $\begin{array}{l}\text { Retained foreign body } \\
\text { Orbital } \\
\text { Lid }\end{array}$ & 2 & 50 \\
\hline Presaptal soft tissue swelling & 1 & 50 \\
\hline Retrobulbar hemorrhage & 2 & 25 \\
\hline Retrobulbar fat stranding & 1 & 25 \\
\hline Optic nerve injury & 1 & 25 \\
\hline
\end{tabular}

Out of 4 traumatic cases fracture was seen in 3 among which MDCT showed 2 (66.66\%) had blow in fracture involving roof, wall (medial wall in one case and lateral wall in another case) and floor or orbit and 1 had blow out fracture which involved medial wall. 2 cases of blow in fractured had comminuted fracture with displaced fracture fragments. Among 2 cases of retained foreign body 1 had orbital foreign body which was seen as an elongated hypodensity (wooden) in medial aspect of orbit causing fracture of medial wall of orbit and extending into ethmoid sinus along with surrounding hemorrhage, retrobulbar fat stranding and preseptal soft tissue thickening. In another case foreign body was located in lower lid which appeared as hyperdense focus along with surrounding inflammatory change seen on MDCT. 


\section{Discussion}

Imaging provides crucial information regarding emergent orbital abnormalities, and the radiologist fulfills an important role in guiding patient care and contributing to favorable outcomes. Knowledge of the imaging features of various orbital conditions is necessary to achieve a prompt and accurate diagnosis, thereby avoiding permanent vision loss and other potentially devastating consequences. The ability of imaging to distinguish pathological entities from physiologic calcifications, post therapeutic changes, and orbital devices allows optimal management without unnecessary further diagnostic work-up. CT and MRI have made significant contributions to the field of ophthalmology. Familiarity with salient imaging features of conditions affecting the eye and orbit help the ophthalmologist to better understand disease process and evaluate response to therapy ${ }^{3}$. CT is the first-line modality for radiologic evaluation of the orbit in the acute setting, with MR imaging serving as a useful secondary diagnostic tool because of its excellent tissue contrast resolution. Computed tomography (CT) has revolutionized the diagnosis and management of ocular and orbital diseases. In addition, knowing the precise location of a lesion facilitates the planning and appropriate surgical approach to minimize morbidity ${ }^{4}$.
Out of total 50 cases in our study, 22 had neoplastic lesions, 15 had infective and inflammatory lesions, 3 had congenital and developmental lesions, 2 had parasitic lesions, 1 had vascular lesion, 3 had miscellaneous lesions (bony and PNS lesions) and 4 had traumatic lesions. In the study done by Durrani et $\mathrm{al}^{5}$ among 26 patients most common lesion was neoplastic (46\%) followed by infections (28\%), inflammation (18\%), trauma (6\%) and vascular $(2 \%)$. Mahsud ${ }^{6}$ study on 50 cases of proptosis showed that 28 were neoplastic, 12 were inflammatory, 7 were congenital and 3 were traumatic in nature. The spectrum of ocular and orbital lesions in our study was similar.

Chinda et $\mathrm{al}^{7}$ studied 49 cases of ocular and orbital tumor and reported that retinoblastoma was the most common tumor accounting for $18(46.15 \%)$ in their study. In a study, Vashisht et $\mathrm{al}^{8}$ reported 30 (30\%) cases of retinoblastoma in a series of total 100 cases of orbital mass. In our study out of 50 cases, retinoblastoma was seen in 12 cases accounting for most common lesion. Arrigg et $\mathrm{al}^{9}$ assessed the role of CT in management of 21 patients with retinoblastoma and found $83 \%$ of tumours showed evidence of calcification and Asih et $\mathrm{al}^{10}$ in their study found calcification in $92 \%$ of RB. In our study calcification was seen in $90.90 \%$ cases of retinoblastoma. Kaste et $\mathrm{al}^{11}$ described three 
pattern of growth (endophytic, exophytic and diffuse infiltrative) of retinoblastoma. In our study 2 pattern of growth (endophytic and exophytic) was seen and in one cases exophytic growth infiltrated reterobulbar region. Two cases bilateral retinoblastoma in our study showed leptomeningeal metastasis on MDCT. Galluzzia et $\mathrm{al}^{12}$ reported that sensitivity of CT scan for detecting retinoblastoma was $81 \%-96 \%$ and also concluded that CT was superior in detecting calcifications which was diagnostic point for retinoblastoma. In our study we found that MDCT had sensitivity of $92.85 \%$, specificity of $97.67 \%$ for detecting retinoblastoma.

Idiopathic orbital pseudotumor (IOP) is a nongranulomatous inflammatory process in the orbit and is the third most common ophthalmologic disease of the orbit and accounts for approximately $8-11 \%$ of all orbital tumors ${ }^{13}$. According to the study done by Chaudhry et al ${ }^{14}$ orbital myositis was common component of orbital pseudotumor and $90-95 \%$ of cases were unilateral, enlarged muscle bellies with thickened tendons was the most common finding. In our study all 3 cases had unilateral eye involvement and MDCT showed ill-defined enlargement of extra ocular muscle right up to its tendinous insertion. Kahaly et $\mathrm{al}^{15}$ reviewed imaging findings in thyroidassociated orbitopathy on CT scan and found symmetrical involvement of extrocular muscles was seen in $30 \%$ cases and most common muscle involved in their study was inferior rectus, medial rectus, superior rectus and lateral rectus in decreasing order with sparing of tendenous insertion. Bagnolesi et $\mathrm{al}^{16}$ reviewed 68 cases to evaluate Graves' ophthalmology with new CT parameters and found increase in both muscular and fatty tissue 54/68 cases and exclusive increase in fatty tissue $14 / 68$ cases. similar to their study all 3 cases in our study showed fusiform enlarged belly of extra ocular muscles with sparing of tendenous insertion along with increased volume of retrobulbar fat leading to proptosis. Most common muscle involved was inferior rectus followed by medial rectus and SR/LPS complex in decreasing frequency.

Computed tomography (CT) is considered to be the top choice for evaluating orbital trauma. $^{40}$ Lee et $\mathrm{al}^{17}$ reported a case of retained wooden foreign body in orbit in 41 yrs old man. CT scan disclosed a foreign body introduced in right medial orbital wall, nasal cavity and ethmoid sinus. Imran et $\mathrm{al}^{18}$ did a cross sectional observational study and found CT scan had higher accuracy compared to ultrasound in detecting intraocular foreign body. Saeed et $\mathrm{al}^{19}$ retrospectively studied the roles of plain X-ray and computed tomography (CT) in 204 consecutive cases of suspected IOFB and concluded that CT of the orbit was the investigation of choice in case of foreign 
body. All the traumatic cases in our study underwent CT scan and the lesion was diagnosed based on imaging findings. CT scan played an important role in diagnosis of traumatic lesions. CT in case of fracture is the imaging method of choice for evaluation of orbital trauma.

LeBedis et $\mathrm{al}^{2}$ described CT as first-line modality for radiological evaluation of orbital trauma. Vashisht et $\mathrm{al}^{8}$ documented the impact of CT scan in localizing and determining the extent of an intra-orbital mass lesion and to predict its nature in 100 patients with suspected orbital mass and found CT scan had accuracy of approximately $86-91 \%$. The diagnostic accuracy of CT scan was $80 \%$ in 50 patient of proptosis in a study done by Mahsud $^{6}$. The range of sensitivity, specificity and accuracy of MDCT for diagnosing non traumatic lesion sin our study were $50-100 \%$, $96.95-100 \%$ and $96-100 \%$ respectively. In our study the patients of some of the pathological conditions were single in number with correct diagnosis on MDCT leading to $100 \%$ sensitivity, specificity and accuracy.

\section{References}

1. Sharma S, Hari S, Srivastava DN. Imaging of the globe and orbit In: Khandelwal N, Chowdhury V, Gupta AK, Mishra NK, Singh $P$, editors. Diagnostic Radiology Neuroradiology
Including Head and Neck Imaging. $3^{\text {rd }}$ edition: Jaypee; 2010: 351-365.

2. LeBedis CA, Sakai O. Nontraumatic Orbital Conditions: Diagnosis with CT and MR Imaging in the Emergent Setting. Radio Graphics 2008; 28:17411753.

3. Marca JA. Diagnosis and management of a wooden orbital foreign body: case report. British Journal of Ophthalmology 1979;63: 848-851.

4. Naik MN, Tourani KL, Sekhar GC, Honavar SG et al. Interpretation of computed tomography imaging of the eye and orbit. A systematic approach 2002; 50(4):339-353.

5. Durrani MYK. Role of CT Scan in Diagnosis of Orbital Masses. International ophthalmology update. Ophthalmic Journal Published from Islamabad, Pakistan 2014;12 (2).

6. Mahsud ZS, Bano S. Diagnostic role of CT scan in proptosis in paediatric age group. JPMI 2004: 18(3):439-446.

7. Chinda D, Samalia MO, Abah ER, Garba F, Rafindadi AL, Adamu A et al. A clinico-pathological study of orbito-ocular tumors: A 5-year review 2012;1(3):145-147.

8. Vashisht SV, Goulatia RK, Dayal Y, Bhargava S. Impact of computrised axial tomography on orbital diagnosis. Indian J Ophthalmol 1983; 
$31: 347-352$.

9. Arrigg PG, Hedges TR, Char DH. Computed tomography in the diagnosis of retinoblastoma. British Journal of Ophthalmology 1983;67:588-591.

10. Asih D, Gatot D, Sitorus RS. Computed tomography findings of retinoblastoma patients. Indonesia Med J Indones 2009;18 (4):239-241.

11. Kaste SC, Jenkins JJ, Pratt CB, Langston JW, Haik BG. Retinoblastoma: Sonographic Findings with Pathologic Correlation in Pediatric Patients. AJR 2000;175: 495 -500.

12. Galluzzia P, Hadjistilianou $T$, Cerase A, Francesco SD, Totid P, Venturia C, Usefullness of CT in the Study Protocol of Retinoblastoma. AJNR 2009; 30:1760-176.

13. Jung BY, Kim YD. Orbital dermoid cysts presenting as subconjunctival fat droplets. Ophthal Plast Reconstr Surg. 2008; 24(4): 327-9.

14. Chaudhry IA, Shamsi FA, Arat YO, Riley FC. Orbital pseudotumor: distinct diagnostic features and management.
Middle east Afr $\mathrm{J}$ aphthalmol 2008;15(1):17-2.

15. Kahaly GJ. Imaging in thyroid-associated orbitopathy. European Journal of Endocrinology 2001;145:107-118.

16. Bagnolesi $\mathrm{P}$, Cilotti A, Campassi C, Lencioni R, Napoli V, Bartolozzi C. Computerized tomography of the orbit in Graves' ophthalmopathy. New observations. Radiol Med. 1992; 83(5):56975.

17. Lee JA, Lee HY. A case of retained wooden foreign body in orbit. Korean $\mathrm{J}$ Ophthalmology 2002; 16:114-118.

18. Imran S, Amin S, Daula MIH. Imaging in Ocular Trauma Optimizing the Use of Ultrasound and Computerised Tomography. Pak J Ophthalmol: 2011; 27 (3):146-151.

19. Saeed A, Cassidy L, Malone DE, Beatty S. Plain X-ray and Computed Tomography of the Orbit in Cases and Suspected Cases of Intraocular Foreign Body. 2008; 22(11):1373-13. 